\title{
NF-KB: a key role in inflammatory diseases
}

\author{
Paul P. Tak ${ }^{1}$ and Gary S. Firestein ${ }^{2}$ \\ ${ }^{1}$ Division of Clinical Immunology and Rheumatology, Academic Medical Center, Amsterdam, The Netherlands \\ ${ }^{2}$ Division of Rheumatology, Allergy and Immunology, University of California at San Diego School of Medicine, La Jolla, California, USA \\ Address correspondence to: Paul P. Tak, Division of Clinical Immunology and Rheumatology, Academic Medical Center, PO Box 22700 , \\ 1100 DE Amsterdam, The Netherlands, Phone: +31-20-5662171; Fax: +31-20-6919658; E-mail: P.P.Tak@amc.uva.nl.
}

Activation of the NF- $\kappa \mathrm{B} /$ Rel transcription family, by nuclear translocation of cytoplasmic complexes, plays a central role in inflammation through its ability to induce transcription of proinflammatory genes (1). This pathway is activated upon appropriate cellular stimulation, most often by signals related to pathogens or stress. Here we will discuss the specificity of various $\mathrm{NF}-\kappa \mathrm{B}$ proteins, their role in inflammatory disease, the regulation of NF- $\kappa$ B activity by I $\mathrm{I} B$ proteins and I $\mathrm{I} B$ kinase (IKK), and the development of therapeutic strategies aimed at inhibition of NF- $\mathrm{KB}$.

Functions of individual NF-KB proteins

in immune cells

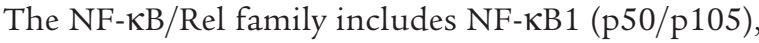
NF-кB2 (p52/p100), p65 (RelA), RelB, and c-Rel (2). Most members of this family (RelB being one exception) can homodimerize, as well as form heterodimers with each other. The most prevalent activated form of $\mathrm{NF}-\mathrm{\kappa B}$ is a heterodimer consisting of a p50 or p52 subunit and p65, which contains transactivation domains necessary for gene induction.

Studies in knockout mice have shown distinct functions for different members of the NF- $\kappa B /$ Rel family. Various NF- $\kappa B$ proteins play a pivotal role in defense of the host against certain pathogens. Furthermore, lack of RelA leads to embryonic lethality and liver degeneration in knockout mice, whereas mice lacking p50 or RelB are immunodeficient but otherwise develop normally to adulthood. B cells from p50 knockout mice show abnormal mitogen responses and antibody production. RelB plays a role in the development and differentiation of dendritic cells, and a mutation disrupting relB impairs antigen presentation. Other NF- $\mathrm{\kappa B}$ proteins, including $\mathrm{C}-\mathrm{Rel}$ and $\mathrm{p} 52$, are also essential for normal immune function. Of interest, unlike either of the corresponding single knockout mice, p50/p52 double knockout mice exhibit impaired development of osteoclasts and B cells (3).

The expression of NF- $\mathrm{KB}$ proteins can provide siteand event-specificity in response to a particular stimulus. For instance, IL-1-induced collagenase expression in synoviocytes is primarily activated by p50 homodimers that bind to a critical NF- $\mathrm{KB}$-like binding site (4). Both p50 and p65 play a role in constitutive IL- 6 pro- duction in rheumatoid arthritis (RA) synovial fibroblasts (5), whereas p65 activation by thrombin regulates ICAM-1 expression in endothelial cells (6). p50 and p 65 heterodimers are intimately involved in activation of inflammatory genes by IL- 1 or TNF- $\alpha$ in human monocytes, and these effects are blocked by the anti-inflammatory cytokine IL-10 (7). Additional specificity is provided by the expression patterns of other regulatory molecules, including surface receptors to proinflammatory cytokines as well as the hierarchy of IKK and IKB isotypes in each cell lineage (see below). These differences, along with multiple variations in $\mathrm{NF}-\kappa \mathrm{B}-$ like binding sites that interact with certain NF- $\kappa B$ hetero- and homodimers, permit cells to respond to the external environment at the appropriate time with the correct genes.

Regulation of NF- $\mathrm{KB}$ activation by IKB and IKKS NF- $\kappa \mathrm{B}$ exists in the cytoplasm in an inactive form associated with regulatory proteins called inhibitors of $\kappa B$ (I $\mathrm{B})$, of which the most important may be $\mathrm{I} \kappa \mathrm{B} \alpha, \mathrm{I} \kappa \mathrm{B} \beta$, and $\mathrm{I} \kappa \mathrm{B} \varepsilon$. As discussed below, $\mathrm{I} \kappa \mathrm{B} \alpha$ is associated with transient NF- $\kappa B$ activation, whereas I $\kappa B \beta$ is involved in sustained activation. I $\mathrm{\kappa} B \alpha$ binds to the p50-p65 heterodimer and the $\mathrm{p} 50$ homodimer, although it does not inhibit DNA binding activity of the latter (8). IкB $\beta$ inhibits p50-p65 more strongly than it inhibits p50-RelB and p50-c-Rel complexes, whereas I $\mathrm{I} B \alpha$ has similar effects on these complexes. In endothelial cells, I $\mathrm{BB} \varepsilon$ is associated with p65 and to a lesser extent with c-Rel, whereas I $\mathrm{I} B \alpha$ and $\mathrm{I} \kappa \mathrm{B} \beta$ associate with $\mathrm{p} 65$, but not c-Rel (9). Hence, different IKB molecules have distinct and overlapping specificities. The tissue distribution may

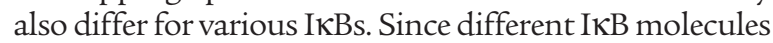
might control the regulation of distinct genes in various

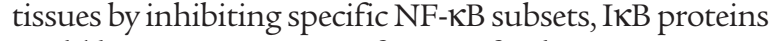
could be attractive targets for specific therapies.

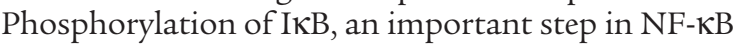
activation, is mediated by IKK. The IKK complex consists of at least three subunits, including the kinases IKK$\alpha$ and IKK- $\beta$ (also called IKK- 1 and IKK-2, respectively), (10) and the regulatory subunit IKK- $\gamma(11)$. An inducible form of IKK, known as IKKi, was recently identified in endotoxin-stimulated immune cells (12). IKK activation initiates I $\mathrm{B} \alpha$ phosphorylation at specific $\mathrm{NH}_{2}$-terminal 
$N F-\kappa B$ in defense and disease

Albert S. Baldwin, Jr., Series Editor

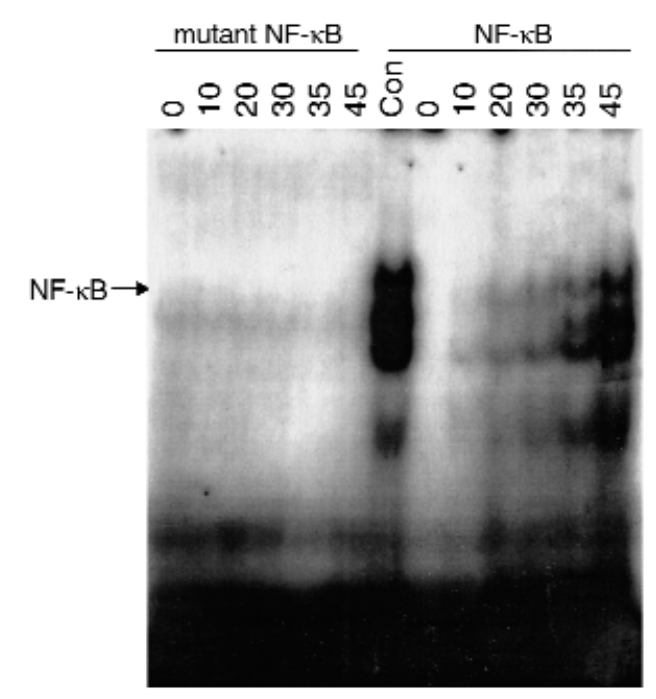

\section{Figure 1}

Activation of NF- $\mathrm{KB}$ in murine $\mathrm{ClA}$. Mice were immunized with type II collagen on days 0 and 20 and boosted with lipopolysaccharide on day 28 . Electromobility shift assays were performed on nuclear extracts of ankle joints at various time points during the evolution of disease. The right side of the gel shows NF-KB binding to labeled consensus NF- KB oligonucleotide, while the left side shows lack of binding to a mutant NF-KB oligonucleotide. Note that NF-KB binding activity was observed as early as 10 days after immunization, even though clinical arthritis was not observed until approximately day 30 . Con, positive control.

serine residues. Phosphorylated IKB $\alpha$ is then ubiquitinated, which targets it for degradation by the $26 \mathrm{~S}$ proteasome (13), thereby releasing NF- $\mathrm{\kappa B}$ dimers from the cytoplasmic NF- $\kappa \mathrm{B}-\mathrm{I} \kappa \mathrm{B}$ complex and allowing them to translocate to the nucleus. NF- $\kappa B$ then binds to $\kappa B$ enhancer elements of target genes, inducing transcription of proinflammatory genes. IKK also phosphorylates $\mathrm{I} \kappa \mathrm{B} \beta$ and $\mathrm{I} \kappa \mathrm{B} \varepsilon$. Phosphorylation of I $\mathrm{I} B \beta$ leads to prolonged NF- $\mathrm{\kappa B}$ activation (14), which can in part be explained by the delay in I $\kappa \mathrm{B} \beta$ resynthesis after degradation. I $\mathrm{KB} \varepsilon$ is degraded with relatively slow kinetics like I $\mathrm{KB} \beta$, but it may also be resynthesized at a rate comparable with that of IKB $\alpha$.

In many cell types, IKK resides at a key convergence site for multiple signaling pathways that lead to NF-KB activation (15). IKK- $\beta$ knockout mice develop liver failure due to hepatocyte apoptosis, especially in the presence of TNF- $\alpha$ (16). Although NF-KB blockade appears to be hepatotoxic during embryonic development, the use of an inducible I $\mathrm{K} \mathrm{B} \alpha$ super-repressor transgene suggests that NF- $\mathrm{kB}$ inhibition is well tolerated in adult mice (17). However, even in that model, NF- $\mathrm{KB}$ blockade compromises normal host defense and leaves mice unable to clear opportunistic infections with Listeria monocytogenes. IKK- $\alpha$ knockouts exhibit abnormal morphogenesis. IKK- $\alpha$ appears to be involved in keratinocyte differentiation and formation of the epidermis (18).
Recent data indicate that activation of IKK- $\beta$, rather than IKK- $\alpha$, participates in the primary pathway by which proinflammatory stimuli induce NF- $\mathrm{KB}$ function (19). IKK- $\beta$ is expressed in fibroblast-like synoviocytes and plays a central role in IL-1- and TNF$\alpha$-mediated NF- $\kappa B$ activation and expression of proinflammatory genes (15). Similarly, IKK- $\beta$ specifically regulates NF- $\kappa B$ activation and inflammatory gene transcription in human monocytes and in human $\mathrm{CD}^{+} \mathrm{T}$ lymphocytes. However, it remains to be determined whether IKK- $\beta$ has a pivotal role in NF- $\kappa B$ activation in all cell types. Upstream of IKK, kinases such as NF- $\kappa \mathrm{B}$-inducing kinase (NIK) and MEKK1 (both members of the mitogen-activated protein kinase kinase kinase [MAPKKK] family) and an IKK-related kinase named NAK (NF-KB-activating kinase) (20) can activate IKK in response to pro-inflammatory stimuli.

\section{Role of the NF-KB pathway in immune responses} and inflammation

Studies in transgenic mice whose $T$ cells lack the NF$\kappa \mathrm{B} /$ Rel signaling pathway show that NF- $\mathrm{KB}$ plays a role in Th1-dependent delayed-type hypersensitivity responses (21). NF- $\mathrm{KB}$ activation increases expression of the adhesion molecules E-selectin, VCAM-1, and ICAM-1, while NF-KB inhibition reduces leukocyte adhesion and transmigration (22). NF- $\mathrm{KB}$ activation is also involved in apoptosis, although its role is not always straightforward. For instance, NF- $\kappa B$ activation may lead to induction of apoptosis in some cell types (2), perhaps because it, along with activator protein 1 (AP-1), can induce FasL expression (23). In other lineages like hepatocytes and synovial cells, NF- $\mathrm{KB}$ plays an antiapoptotic role $(24,25)$. Inhibition of NF$\mathrm{\kappa B}$-induced caspase-8 activation (25) might be one of the mechanisms by which targeting NF-KB may lead to protection against apoptosis. This protective function may be regulated by Akt, which could contribute to the ability of PDGF to serve as a cell survival signal (26).

$\mathrm{NF}-\mathrm{KB}$ is clearly one of the most important regulators of proinflammatory gene expression. Synthesis of cytokines, such as TNF- $\alpha$, IL-1 $\beta$, IL- 6 , and IL-8, is mediated by NF- $\mathrm{KB}$, as is the expression of cyclooxygenase 2 (Cox-2). Aupperle et al. (15) recently studied the consequences of IKK in primary fibroblast-like synoviocytes isolated from synovium of patients with RA and osteoarthritis. In both groups, immunoreactive IKK protein is abundant in these cells, and IKK- $\alpha$ and IKK- $\beta$ are constitutively expressed at the mRNA level. IKK function in these cells can be greatly enhanced by TNF- $\alpha$ and IL- 1 , leading to degradation of endogenous I $\mathrm{K} B \alpha$ and nuclear translocation of NF-KB. Activation of this pathway and the consequent induction of IL-6, IL-8, ICAM-1, and collagenase-1 expression depends specifically on IKK- $\beta(15)$. Thus, transfection with adenoviral constructs encoding an IKK- $\beta$ dominant-negative mutant prevents TNF$\alpha$-mediated NF- $\kappa B$ nuclear translocation and proin- 
flammatory gene expression in synoviocytes, whereas dominant-negative IKK- $\alpha$ mutant has no effect (15).

$\mathrm{NF}-\kappa \mathrm{B}$ is also able to function in concert with other transcription factors, such as AP-1. For instance, NF- $\kappa B$ translocation can enhance transcription of the collagenase-3 (MMP13) gene in IL-1-stimulated synoviocytes (27). Full expression of collagenase gene transcription, however, depends on the participation of AP1 , whose transcriptional induction follows a distinct pathway involving phosphorylation of the MAPK c-Jun $\mathrm{NH}_{2}$-terminal kinase (JNK), with subsequent phosphorylation of c-Jun. Therefore, the signal transduction cascade after cytokine stimulation of synoviocytes results in the activation of parallel kinase cascades regulating AP-1 and NF- $\mathrm{BB}$. This dual pathway enhances production of some proinflammatory cytokines (like TNF- $\alpha$ ), and, more strikingly, increases expression of the destructive enzymes that regulate matrix remodeling (28). Hence, AP-1 and NF- $\mathrm{KB}$ are simultaneously activated in IL- 1 or TNF- $\alpha$-stimulated synoviocytes as well as the intimal synovial lining of RA patients (29), which is the site in vivo where matrix metalloproteinases (MMPs) are produced. Coordinate stimulation of NF- $\mathrm{KB}$ and AP-1 can thereby contribute to bone and cartilage destruction in the joint.

$\mathrm{NF}-\kappa \mathrm{B}$ activation in animal models of inflammation Animal models of inflammatory arthritis support the notion that NF- $\kappa B$ activation plays a pathogenic role in vivo. For instance, increased synovial NF- $\kappa B$ binding precedes the development of clinical joint involvement in murine collagen-induced arthritis (CIA) and gradually increases during the evolution of disease (29) (Figure 1). Much of this binding activity appears to be due to p50, which has been implicated in collagenase-3 transcription and could contribute, along with locally activated AP-1, to extracellular matrix resorption. Synovial NF- $\kappa \mathrm{B}$ activation also occurs within a few days after immunization in rat adjuvant arthritis (30). Selective activation of NF- $\kappa \mathrm{B}$ in normal rats by intra-articular transfer of a functional IKK- $\beta$ gene leads to synovial inflammation and clinical signs of arthritis (31). Conversely, reduction of NF- $\kappa \mathrm{B}$ nuclear translocation and clinical synovitis was observed in adjuvant arthritis in rats after an intra-articular injection with a dominantnegative adenoviral IKK- $\beta$ construct (31). The central role of NF- $\kappa B$ in inflammation has also been shown in rats with streptococcal cell wall-induced arthritis (24) and in mice with CIA $(29,32)$.

$\mathrm{NF}-\kappa \mathrm{B}$ has also been implicated in several other tissuespecific models of inflammation. NF- $\kappa \mathrm{B}$ activation induces production of proinflammatory cytokines in nephritic glomeruli, resulting in experimental glomerulonephritis in rats (33). IL-2 knockout mice develop an inflammatory colitis that is marked by increased IL-1 expression (34). These changes are accompanied by enhanced NF- $\mathrm{KB}$ activation in colonic epithelium, although it is not certain whether the increases in proinflammatory cytokine production are the cause or result of NF- $\mathrm{KB}$ binding. In allergen-induced asthma, loss of the p50 locus in knockout mice ablates the eosinophilic airway response (35). These animals produce reduced levels of the Th2 cytokine IL-5, along with MIP- $1 \alpha$ and MIP-1 $\beta$, which are implicated in the recruitment of mononuclear cells to the site of inflammation. Similarly, c-Rel knockout mice have decreased airway hyperresponsiveness and eosinophil infiltration as well as lower levels of serum $\operatorname{IgE}$ in an allergen-induced asthma model (36). These observations support the notion that $\mathrm{NF}-\kappa \mathrm{B}$ plays an important role in many different inflammatory disorders.

NF- $K B$ activation in human inflammatory diseases $\mathrm{NF}-\kappa \mathrm{B}$ is highly activated at sites of inflammation in diverse diseases (Table 1) and can induce transcription of proinflammatory cytokines, chemokines, adhesion molecules, MMPs, Cox-2, and inducible nitric oxide

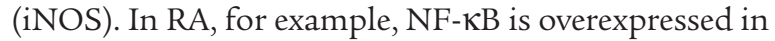
the inflamed synovium (29), where its activity may enhance recruitment of inflammatory cells and production of proinflammatory mediators like IL-1, IL-6, IL-8, and TNF- $\alpha$. Both p50 and p65 have been localized to nuclei in synovial lining cells as well as mononuclear cells in the sublining regions. Electrophoretic mobility shift assays demonstrate that NF- $\mathrm{KB}$ binding to DNA is much greater in RA compared with osteoarthritis controls, consistent with increased proinflammatory cytokine production in the former (29).

Inflammatory airway disease in humans has also been associated with cytokine and adhesion molecule expression. This correlates with activation of NF- $\mathrm{KB}$ in bronchial biopsies from asthma patients (37). Increased NF- $\kappa \mathrm{B}$ activity with nuclear localization was observed especially in airway epithelial cells, where there is abundant expression of proinflammatory cytokines, chemokines, iNOS, and Cox-2.

Helicobacter pylori-associated gastritis is also marked by increased NF- $\kappa \mathrm{B}$ activity in gastric epithelial cells (38). The number of NF- $\kappa B$ positive cells correlates with the degree of gastritis. Similarly, there is evidence of NF- $\kappa \mathrm{B}$ activation in inflammatory bowel disease, where lamina propria macrophages display activated

\section{Table 1}

NF-KB-activation inflammatory disease

\section{Rheumatoid arthritis}

Atherosclerosis

Multiple sclerosis

Chronic inflammatory demyelinating polyradiculoneuritis

Asthma

Inflammatory bowel disease

Helicobacter pylori-associated gastritis

Systemic inflammatory response syndrome 
Table 2

Therapeutic strategies aimed at blocking NF-KB activity

IKK- $\beta$-dominant-negative gene therapy

NF-KB decoy oligonucleotides

T-cell specific NF- $\kappa B$ inhibitor

Corticosteroids

Sulfasalazine

5-aminosalicylic acid

Aspirin

Tepoxalin

Leflunomide

Curcumin

Antioxidants

Proteasome inhibitors

p50, c-Rel, and especially p65. In vitro treatment of these cells with antisense p65 oligonucleotides reduced proinflammatory cytokine production (39). Neurological disease (see article by Mattson and Camandola, this series, ref. 40) and inflammation associated with atherosclerosis (see article by Collins and Cybulsky, this series, ref. 41) are also mediated, in part, by NF-кB.

NF- $K B$-directed therapies in animal models and in human disease

The identification of NF- $\mathrm{KB}$ as a key player in the pathogenesis of inflammation suggests that NF- $\mathrm{KB}$-targeted therapeutics might be effective in diseases like RA. This view is supported by the effects of various therapeutic strategies aimed at blocking NF- $\kappa \mathrm{B}$ activity. As noted above, inhibition of IKK- $\beta$ activity markedly ameliorates adjuvant-induced arthritis (31). NF- $\mathrm{KB}$ blockade with $\mathrm{NF}-\kappa \mathrm{B}$ decoy oligonucleotides, either by direct injection or by viral gene transfer, inhibits the development of streptococcal cell wall-induced arthritis and CIA in rats $(24,42)$, perhaps by increasing apoptosis and suppressing cytokine gene expression. Inhibition of NF- $\mathrm{KB}$ in $\mathrm{T}$ cells in transgenic mice overexpressing I $\mathrm{I} B \alpha$ resulted in decreased incidence and severity of CIA (43). In agreement with these observations, treatment with a T-cell specific NF- $\kappa \mathrm{B}$ inhibitor significantly decreased arthritis severity in CIA in mice (32). NF- $\mathrm{KB}$-directed therapy is also effective in a model of inflammatory bowel disease induced by 2, 4, 6,-trinitrobenzene sulfonic acid. Local application of p65 antisense oligonucleotides blocks both clinical and histologic evidence of disease activity (44). Thus, the feasibility and efficacy of specific inhibition of NF- $\kappa$ B activity has been shown in several animal models of inflammatory disease.

A variety of drugs used to treat human inflammatory disease have effects on NF- $\mathrm{KB}$ activity (Table 2; see article by Yamamoto and Gaynor, this series, ref. 45). For example, some of the effects of corticosteroids, used in the treatment of inflammatory bowel disease, asthma, psoriasis, and RA, are probably mediated through the inhibition of NF- $\mathrm{KB}$ activation. Other examples of small molecules include sulfasalazine and its salicylate moiety 5-aminosalicylic acid, aspirin, and other nonsteroidal anti-inflammatory drugs, and leflunomide. Sulfasalazine and leflunomide block nuclear translocation of NF- $\kappa B$ through inhibition of $I \kappa B \alpha$ degradation. This might be caused by a direct effect on IKK or upstream signals. Aspirin appears to function as a competitive inhibitor of IKK- $\beta$. These drugs are, however, not specific, and require relatively high concentrations to achieve effective NF- $\kappa B$ inhibition. Agents that block proximal cytokines, such as IL- 1 and TNF- $\alpha$, also limit $\mathrm{NF}-\kappa \mathrm{B}$ activation and inhibit the inflammatory cascade. Blocking individual cytoplasmic components of the IKK activation pathway, including TRADD, RIP, TRAF2 , and TRAF-6, might in part have similar effects, although this remains to be shown in animal models and human disease. Moreover, these molecules may not be essential for NF- $\kappa \mathrm{B}$ activation.

IKK- $\beta$ is essential for TNF- $\alpha$ - and IL-1-induced $\mathrm{NF}-\kappa \mathrm{B}$ activation and therefore represents a potential target for strategies aimed at inhibiting proinflammatory gene expression for the treatment of a variety of inflammatory disorders, especially RA (46). It is conceivable that blockade of specific subsets of the $\mathrm{NF}-\kappa \mathrm{B} /$ Rel family could be used to inhibit inflammatory disease. The ability to identify individual components as key to a particular disease will be essential to developing specific therapeutics (like IKK- $\beta$ in RA synoviocytes). In inflammatory bowel disease, for instance, the apparent importance of p65 suggests that therapeutic agents directed at this protein might be useful.

Of some concern is the potential for toxicity since $\mathrm{NF}-\kappa \mathrm{B}$ blockade could result in liver apoptosis, especially in the presence of TNF- $\alpha$. This issue is clearly relevant in RA where TNF- $\alpha$ overproduction is a hallmark of the disease. The ultimate benefit of such targeted therapy will depend on the delicate balance between suppressing inflammation and interfering with normal cellular functions. By selectively targeting specific NF- $\kappa$ B subunits, I $\kappa B$ proteins, or kinases that have a degree of tissue specificity, one might attain therapeutic efficacy and minimize systemic toxicity.

1. Baldwin, A.S., Jr. 1996. The NF-kappa B and I kappa B proteins: new discoveries and insights. Annu. Rev. Immunol. 14:649-683.

2. Chen, F., Castranova, V., Shi, X., and Demers, L.M. 1999. New insights into the role of nuclear factor-kappaB, a ubiquitous transcription factor in the initiation of diseases. Clin. Chem. 45:7-17.

3. Franzoso, G., et al. 1997. Requirement for NF-kappaB in osteoclast and B-cell development. Genes Dev. 11:3482-3496.

4. Vincenti, M.P., Coon, C.I., and Brinckerhoff, C.E. 1998. Nuclear factor $\mathrm{kappaB} / \mathrm{p} 50$ activates an element in the distal matrix metalloproteinase 1 promoter in interleukin-1beta-stimulated synovial fibroblasts. Arthritis Rheum. 41:1987-1994.

5. Miyazawa, K., Mori, A., Yamamoto, K., and Okudaira, H. 1998. Constitutive transcription of the human interleukin- 6 gene by rheumatoid synoviocytes: spontaneous activation of NF-kappa B and CBF1. Am. J. Pathol. 152:793-803.

6. Rahman, A., Anwar, K.N., True, A.L., and Malik, A.B. 1999. Thrombininduced 965 homodimer binding to downstream NF-kappa B site of the promoter mediates endothelial ICAM-1 expression and neutrophil adhe- 
sion. Immunol $\mathbf{1 6 2 \cdot 5 4 6 6 - 5 4 7 6 . ~}$

7. Schottelius, A.J., Mayo, M.W., Sartor, R.B., and Baldwin, A.S., Jr. 1999 Interleukin-10 signaling blocks inhibitor of kappaB kinase activity and nuclear factor kappaB DNA binding. J. Biol. Chem. 274:31868-31874

8. Li, Z., and Nabel, G.J. 1997. A new member of the I kappaB protein family, I kappaB epsilon, inhibits RelA (p65)-mediated NF-kappaB transcription. Mol. Cell Biol. 17:6184-6190.

9. Spiecker, M., Darius, H., and Liao, J.K. 2000. A functional role of I kappa B-epsilon in endothelial cell activation. J. Immunol. 164:3316-3322.

10. Zandi, E., Chen, Y., and Karin, M. 1998. Direct phosphorylation of IkappaB by IKKalpha and IKKbeta: discrimination between free and NF-kappaB-bound substrate. Science. 281:1360-1363.

11. Yamaoka, S., et al. 1998. Complementation cloning of NEMO, a component of the IkappaB kinase complex essential for NF-kappaB activation. Cell. 93:1231-1240.

12. Shimada,T., et al. 1999. IKK-i, a novel lipopolysaccharide-inducible kinase that is related to IkappaB kinases. Int. Immunol. 11:1357-1362.

13. Chen, Z., et al. 1995. Signal-induced site-specific phosphorylation targets I kappa B alpha to the ubiquitin-proteasome pathway. Genes Dev. 9:1586-1597.

14. Thompson, J.E., Phillips, R.J., Erdjument-Bromage, H., Tempst, P., and Ghosh, S. 1995. I kappa B-beta regulates the persistent response in a biphasic activation of NF-kappa B. Cell. 80:573-582.

15. Aupperle, K.R., et al. 1999. NF-kB regulation by IkB kinase in primary fibroblast-like synoviocytes. J. Immunol. 163:427-433.

16. Li, Z.W., et al. 1999. The IKKbeta subunit of IkappaB Kinase (IKK) is essential for nuclear factor kappaB activation and prevention of apoptosis. J. Exp. Med. 189:1839-1845.

17. Lavon, I., et al. 2000. High susceptibility to bacterial infection, but no liver dysfunction, in mice compromised for hepatocyte NF-kappaB activation. Nat. Med. 6:573-577.

18. Hu, Y., et al. 1999. Abnormal morphogenesis but intact IKK activation in mice lacking the IKKalpha subunit of IkappaB kinase. Science. 284:316-320.

19. Delhase, M., Hayakawa, M., Chen, Y., and Karin, M. 1999. Positive and negative regulation of IkappaB kinase activity through IKKbeta subunit phosphorylation. Science. 284:309-313.

20. Tojima, Y., et al. 2000. NAK is an IkappaB kinase-activating kinase. Nature. 404:778-782.

21. Aronica, M.A., et al. 1999. Preferential role for NF-kappa B/Rel signaling in the type 1 but not type $2 \mathrm{~T}$ cell-dependent immune response in vivo. $J$. Immunol. 163:5116-5124.

22. Chen, C.C., Rosenbloom, C.L., Anderson, D.C, and Manning A.M. 1995. Selective inhibition of E-selectin, vascular cell adhesion molecule-1, and intercellular adhesion molecule-1 expression by inhibitors of I kappa B alpha phosphorylation. J. Immunol. 155:3538-3545.

23. Kasibhatla, S., et al. 1998. DNA damaging agents induce expression of Fas ligand and subsequent apoptosis in Tlymphocytes via the activation of NF-kappa B and AP-1. Mol. Cell. 1:543-551.

24. Miagkov, A.V., et al. 1998. NF-kappaB activation provides the potential link between inflammation and hyperplasia in the arthritic joint. Proc Natl. Acad. Sci. USA. 95:13859-13864.

25. Wang, C.Y., Mayo, M.W., Korneluk, R.G., Goeddel, D.V., and Baldwin, A.S., Jr. 1998. NF-kappaB antiapoptosis: induction of TRAF1 and TRAF2 and c-IAP1 and c-IAP2 to suppress caspase-8 activation. Science. 281:1680-1683.

26. Romashkova, J.A., and Makarov, S.S. 1999. NF-kappaB is a target of AKT in anti-apoptotic PDGF signalling. Nature. 401:86-90.
27. Mengshol, J.A., Vincenti, M.P., Coon, C.I., Barchowsky, A., and Brinckerhoff, C.E. 2000. Interleukin-1 induction of collagenase 3 (matrix metalloproteinase 13) gene expression in chondrocytes requires p38, c-Jun Nterminal kinase, and nuclear factor kappaB: differential regulation of collagenase 1 and collagenase 3. Arthritis Rheum. 43:801-811.

28. Yokoo, T., and Kitamura, M. 1996. Dual regulation of IL-1 beta-mediated matrix metalloproteinase- 9 expression in mesangial cells by NF-kappa $\mathrm{B}$ and AP-1. Am. J. Physiol. 270:F123-F130.

29. Han, Z.N., Boyle, D.L., Manning, A.M., and Firestein, G.S. 1998. AP-1 and NF-kappa B regulation in rheumatoid arthritis and murine collageninduced arthritis. Autoimmunity. 28:197-208.

30. Tsao, P.W., et al. 1997. The effect of dexamethasone on the expression of activated NF-kappa B in adjuvant arthritis. Clin. Immunol. Immunopathol. 83:173-178

31. Tak, P.P., et al. 1999. IkB kinase-2 (IKK-2) is a key regulator of synovial inflammation. Arthritis Rheum. 42:S400. (Abstr.)

32. Gerlag, D.M., et al. 2000. Effect of a T cell specific NF-kB inhibitor on in vitro cytokine production and collagen-induced arthritis. J. Immunol. 165:1652-1658.

33. Sakurai, H., et al. 1996. Activation of transcription factor NF-kappa B in experimental glomerulonephritis in rats. Biochim. Biophys. Acta. 1316:132-138.

34. Yang, F., de Villiers, W.J., Lee, E.Y., McClain, C.J., and Varilek, G.W. 1999. Increased nuclear factor-kappaB activation in colitis of interleukin-2-deficient mice. J. Lab. Clin. Med. 134:378-385.

35. Yang, L., et al. 1998. Essential role of nuclear factor kappaB in the induction of eosinophilia in allergic airway inflammation. J. Exp. Med. 188:1739-1750.

36. Donovan, C.E., et al. 1999. NF-kappa B/Rel transcription factors: c-Rel promotes airway hyperresponsiveness and allergic pulmonary inflammation. J. Immunol. 163:6827-6833.

37. Hart, L.A., Krishnan, V.L., Adcock, I.M., Barnes, P.J., and Chung, K.F. 1998. Activation and localization of transcription factor, nuclear factor-kap$\mathrm{paB}$, in asthma. Am. J. Respir. Crit. Care Med. 158:1585-1592.

38. van Den Brink, G.R., et al. 2000. Expression and activation of NF-kappa $B$ in the antrum of the human stomach. J. Immunol. 164:3353-3359.

39. Neurath, M.F., et al. 1998. Cytokine gene transcription by NF-kappa B family members in patients with inflammatory bowel disease. Ann. NY Acad. Sci. 859:149-159.

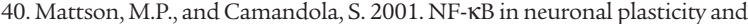
neurodegenerative disorders. J. Clin. Invest. In press.

41. Collins, T., and Cybulsky, M.I. 2001. NF-kB: pivotal mediator or innocent bystander in atherogenesis? J. Clin. Invest. In press.

42. Tomita, T., et al. 1999. Suppressed severity of collagen-induced arthritis by in vivo transfection of nuclear factor kappa B decoy oligodeoxynucleotides as a gene therapy. Arthritis Rheum. 42:2532-2542.

43. Seetharaman, R., Mora, A.L., Nabozny, G., Boothby, M., and Chen, J. 1999. Essential role of T cell NF-kappa B activation in collagen-induced arthritis. J. Immunol. 163:1577-1583.

44. Neurath, M.F., Pettersson, S., Meyer zum Buschenfelde, K.H., and Strober, W. 1996. Local administration of antisense phosphorothioate oligonucleotides to the p65 subunit of NF-kappa B abrogates established experimental colitis in mice. Nat. Med. 2:998-1004.

45. Yamamoto, Y., and Gaynor, R.B. 2001. Therapeutic potential of inhibition of the NF- $\mathrm{KB}$ pathway in the treatment of inflammation and cancer. $J$. Clin. Invest. In press.

46. Firestein, G.S., and Manning, A.M. 1999. Signal transduction and transcription factors in rheumatic disease. Arthritis Rheum. 42:609-621. 